\title{
Meta-analysis of the association between angiotensin pathway inhibitors and COVID- 19 severity and mortality
}

\author{
Malindu E. Fernando ${ }^{1,3}$, Aaron Drovandi ${ }^{1}$ and Jonathan Golledge ${ }^{1,2,3^{*}}$
}

\begin{abstract}
Background: Conflicting findings and the analysis of unpublished and retracted data have led to controversy on the safety of angiotensin-converting enzyme inhibitors and angiotensin receptor blockers in people with COVID-19 infection. This meta-analysis examined the association of prescription of angiotensin-converting enzyme inhibitors (ACEI) and angiotensin receptor blockers (ARB) with the outcome from COVID-19.

Methods: A systematic search was conducted to find published studies that reported the outcome of COVID-19 in relation to prescription of ACEI or ARB. Two authors (MF and AD) independently screened and extracted data and assessed study quality and strength of association using standardised tools. The endpoints for the meta-analyses were severe or critical disease outcome and mortality based on standardised criteria.

Results: Twenty-six studies including 8389 people prescribed ACEl or ARB and 20,989 people not prescribed these medications were included. The quality of studies varied, and the overall strength of association was poor with a high risk of confounding bias. Patients prescribed ACEI or ARB had a greater prevalence of risk factors. Meta-analysis found an association between prescription of ACEl or ARB with severe or critical disease outcome (risk ratio, RR, $1.23,95 \%$ confidence interval, $\mathrm{Cl}, 1.06$ to $1.42, p=0.006, P=88 \%$ ) but this association was lost in sensitivity analyses. There was no association between ACEI or ARB prescription and mortality (RR $1.18,95 \% \mathrm{Cl} 0.92$ to $1.50, p$ $=0.19, P^{2}=82 \%$.

Conclusions: This meta-analysis suggests that people prescribed ACEl or ARB more commonly had severe or critical disease outcome, but not mortality, in published cohorts of patients diagnosed with COVID-19. This finding is most likely due to a greater prevalence of risk factors in these patients rather than due to exposure to angiotensin pathway inhibitors.
\end{abstract}

Keywords: 2019 novel coronavirus disease, Angiotensin-converting enzyme inhibitors, Angiotensin receptor blockers, COVID-19

\footnotetext{
* Correspondence: jonathan.golledge@jcu.edu.au

${ }^{1}$ Queensland Research Centre for Peripheral Vascular Disease, College of

Medicine and Dentistry, James Cook University, Townsville, Queensland 4811,

Australia

${ }^{2}$ Department of Vascular and Endovascular Surgery, Townsville University

Hospital, Townsville, Queensland, Australia

Full list of author information is available at the end of the article
}

C C The Author(s). 2021 Open Access This article is licensed under a Creative Commons Attribution 4.0 International License, which permits use, sharing, adaptation, distribution and reproduction in any medium or format, as long as you give appropriate credit to the original author(s) and the source, provide a link to the Creative Commons licence, and indicate if changes were made. The images or other third party material in this article are included in the article's Creative Commons licence, unless indicated otherwise in a credit line to the material. If material is not included in the article's Creative Commons licence and your intended use is not permitted by statutory regulation or exceeds the permitted use, you will need to obtain permission directly from the copyright holder. To view a copy of this licence, visit http://creativecommons.org/licenses/by/4.0/. The Creative Commons Public Domain Dedication waiver (http://creativecommons.org/publicdomain/zero/1.0/) applies to the data made available in this article, unless otherwise stated in a credit line to the data. 


\section{Introduction}

The SARS-CoV-2 virus, which is responsible for COVID-19, is believed to bind to host cells via angiotensin-converting enzyme 2 (ACE2) [1]. ACE2 expression in some experimental models is altered (both up and downregulation has been reported) by the commonly used antihypertensive drugs angiotensinconverting enzyme inhibitors (ACEI) and angiotensin receptor blockers (ARB) [2, 3]. Meta-analyses suggest that people with a history of hypertension have poor outcomes from COVID-19 $[4,5]$ that could conceivably be due to the prescription of ACEI or ARBs [6].

A number of previous meta-analyses and reviews have explored the association of ACEI and ARB exposure with the outcome of COVID-19 but the findings have been inconsistent [7-11]. Some have reported no significant association between ACEI or ARB prescription and outcome [7-9], whilst others have found reduced mortality in patients prescribed these medications [10, 11]. These previous reviews have had a number of deficiencies, including failure to assess the quality of the included studies and limited examination of the strength of associations identified. Previous analyses have also included unpublished and later retracted studies, leading to concerns about the validity of findings [12]. Furthermore, many new relevant studies have since been published. The aim of this systematic review was to provide an up-to-date and robust assessment of the association of ACEI and ARB exposure with the outcome of COVID-19.

\section{Material and methods}

\section{Search strategy}

This systematic review and meta-analysis was conducted according to the Preferred Reporting Items for Systematic reviews and Meta-Analyses (PRISMA) statement and the Meta-analysis Of Observational Studies in Epidemiology (MOOSE) reporting standards [13, 14]. The final search for original studies was performed on the 19th of June 2020 using multiple databases [MEDLINE via OvidSP, and PubMed]. The search string is shown in S1: Text Box 1. Reference lists of identified publications were hand searched to identify other potentially eligible studies.

\section{Inclusion of studies}

Prospective or retrospective cohort and case-control studies reporting the outcome from COVID-19 in relation to ACEI and/or ARB prescription were eligible for inclusion. Animal studies, reviews and editorials were excluded. Only articles published in English were included and there were no restrictions on publication date. Titles and abstracts of publications identified were screened by two authors (MF, AD) to find studies meeting the eligibility criteria. The full texts of publications that appeared relevant were reviewed by both authors and a decision regarding inclusion made by consensus with the third author (JG).

\section{Definitions of COVID-19, risks factors, drug exposure and outcomes}

COVID-19 diagnosis was based on World Health Organisation (WHO) interim laboratory testing for COVID-19 criteria [15]. Hypertension, diabetes, ischaemic heart disease (IHD), chronic obstructive pulmonary disease (COPD), congestive cardiac failure (CCF) and chronic kidney disease (CKD) were defined by prior diagnosis on electronic medical records as per the international statistical classification of diseases and related health problems version 10 (ICD-10) [16]. Medications, including $\mathrm{ACEI}$ or $\mathrm{ARB}$, were based on record of drug prescription at the time of hospital admission. The primary outcomes were severe or critical disease and mortality according to a report of the WHO-China Joint Mission on COVID-19 [17]. Severe disease was defined as the presence of tachypnoea ( $\geq 30$ breaths/min), oxygen saturation $\leq 93 \%$ at rest, arterial oxygen tension $\left(\mathrm{PaO}_{2}\right)$ over inspiratory oxygen fraction $\left(\mathrm{FIO}_{2}\right) \mathrm{PaO} 2 /$ FiO2 ratio of $<300 \mathrm{mmHg}$, or a clinical diagnosis of ARDS or prolonged hospitalisation ( $\geq 10$ days) [17]. Critical disease was defined as people with respiratory failure requiring mechanical ventilation, shock or other organ failure that requires intensive care. A severe or critical disease outcome of COVID-19 was defined to include both severe and critical disease definitions or death. Mortality was defined as any in-hospital death where COVID-19 was thought to have contributed, as per the WHO guidelines [18]. Exposure to ACEI and/or ARB prescription was defined as a prescription of these medication classes preceding a diagnosis of COVID-19 irrespective of continued medication use at the time of hospitalisation.

\section{Data extraction}

Data extracted included the number of primary outcome events in relation to prescription of ACEI/ARB (exposure), the country where the study took place, study design, sample size, age, sex, hypertension, prescribed antihypertensive medications, comorbidities, systolic and diastolic blood pressure $(\mathrm{mmHg})$ and biochemical data at admission [potassium $(\mathrm{mmol} / \mathrm{l})$, creatinine $(\mu \mathrm{mol} / \mathrm{L})$, estimated glomerular filtrated rate $\left(\mathrm{ml} / \mathrm{min}\right.$ per $\left.1.73 \mathrm{~m}^{2}\right)$ and C-reactive protein (CRP) $(\mathrm{mg} / \mathrm{L})]$. All data were independently extracted by two authors (MF, AD) using a standardised template and inconsistencies were resolved through discussion with a third author (JG). The definitions used by studies are reported in S1: Supp Table 1. To obtain missing data or clarify any discrepancies, 
corresponding authors of all studies were contacted via email, of whom 13 responded. Five authors replied with additional data [19-23], and eight authors responded but could not provide additional data [21, 24-30]. A number of publications reported potentially overlapping data through utilising the same hospitals during the same time period $[11,19,31-33]$ and therefore sensitivity analyses were performed whilst excluding and including these studies.

\section{Quality assessment}

Two assessors (MF, AD) independently evaluated the quality of studies using a modified version of the Risk Of Bias In Non-randomised Studies of Interventions tool [34]. The items assessed included participant selection bias, information bias of study outcomes, definition of exposure of ACEI/ARB prescription, reporting bias due to missing data and the risk of confounding [34]. Any inconsistencies were resolved through discussion until consensus was reached. Each item (10 questions) was assessed as yes, no or not reported. A "yes" was scored as 1 and a "no" or "not reported" as 0 . The scoring of all items was then summed and presented as a percentage of the total possible score of 10 . The final agreed and individual quality scores and degree of agreement were reported.

\section{Evaluating the strength of association}

Two assessors (MF, AD) independently evaluated the strength of association between ACEI/ARB prescription and COVID-19 outcome using relevant components of the Sir Bradford Hill Criteria: dose response relationship, temporal sequence and protopathic bias (timing and duration of ACEI/ARB prescription), biological plausibility and specificity of exposure and outcome [35].

\section{Statistical analysis}

The main meta-analysis examined the association between exposure to ACEI or ARBs (as a combined group) and outcome from COVID-19. Subgroup analyses were performed to examine the associations of ACEI prescription alone or $A R B$ prescription alone with outcome. Leave-one-out sensitivity analyses were performed to assess the contribution of each study to the pooled estimates by excluding individual studies one at a time and recalculating the pooled estimates [36]. Sensitivity analyses were also performed focusing on people with a history of hypertension alone, excluding potential overlapping cohorts and focusing on studies from individual continents (Asia, USA or Europe) and highquality investigations (defined as quality assessment scores $\geq 90 \%$ ). All meta-analyses were performed using Mantel-Haenszel's statistical method and random effect models anticipating substantial heterogeneity [37]. The results were reported as risk ratios (RR) and 95\% confidence intervals $(\mathrm{CI})$. All statistical tests were two-sided and a $p$ value $<0.05$ was considered significant. Heterogeneity was assessed using the $\mathrm{I}^{2}$ statistic values (interpreted as 0 to $49 \%$ : low, 50 to $74 \%$ : moderate and 75 to 100\%: high) [38]. Publication bias was assessed by funnel plots comparing the summary estimate of each study and its precision (1/standard error) [36]. All analyses were conducted using Review Manager 5 (RevMan 5) version 5.3. (Copenhagen: Nordic Cochrane Centre, The Cochrane Collaboration, 2014).

\section{Results}

\section{Search results}

Twenty-six studies from 664 identified articles met the eligibility criteria and were included (Fig. 1) [19-33, 39-49].

\section{Cohort characteristics}

Thirteen studies were from China, five from Italy, three from the USA and one each from Denmark, Spain, Korea, the UK and France. A total of 29,378 out of 44,454 people diagnosed with COVID-19 comprising 8389 people who were prescribed ACEI/ARB and 20,989 people not prescribed ACEI/ARB were included in the meta-analysis (S1: Supp Table 2-3). The characteristics of participants stratified by the prescription of ACEI/ ARB are reported in Table 1. The weighted average age of people prescribed ACEI/ARB was higher than the control group (70 years vs. 56 years). Participants in the ACEI/ARB group were more likely to be male (58\% vs. $50 \%$ ) and have hypertension ( $92 \%$ vs. 39\%), diabetes (30\% vs. $11 \%)$, IHD ( $21 \%$ vs. $7 \%)$, CCF ( $14 \%$ vs. $3 \%)$. CKD (10\% vs. $3 \%)$ and COPD (12\% vs. $7 \%)$ than those not prescribed these drugs. Additional data including blood pressure, $\mathrm{C}$-reactive protein, incidence of severe or critical disease and mortality according to ACEI/ARB and differences in the inpatient use of steroids and antiviral medications stratified by groups is reported in S1: Supp Table 2-6.

\section{Study quality and strength of association}

Quality scores from the two assessors are reported in S1: Supp Table 7. There was agreement on 233 of the $260(90 \%)$ assessments made. The final quality assessments reached after a consensus meeting are reported in Table 2. The overall quality of studies ranged from $20 \%$ (low) to $90 \%$ (high). All but eight articles reported on participant selection bias [19, 23, 25, 31, 33, 41, 45, 46]. All studies except three $[22,27,44]$ reported the method of COVID-19 diagnosis (S1: Supp Table 1), but two studies [31, 46] included people with computed tomography-based diagnoses and two studies did not confirm all diagnoses with PCR $[25,31]$. All but six studies provided outcome definitions for COVID-19 related 


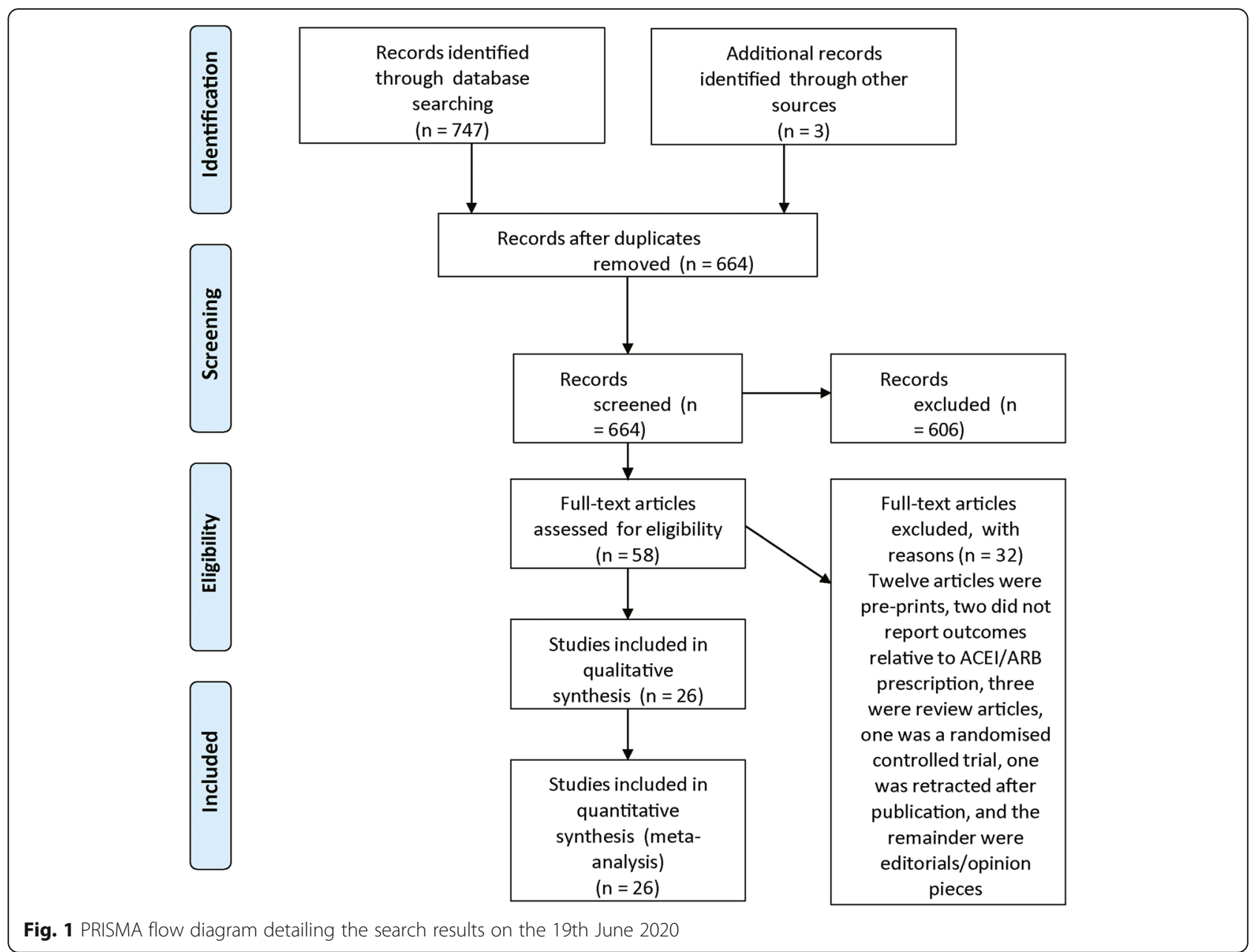

mortality $[20,21,28,29,43,48]$. Thirteen studies provided a clear or surrogate definition for severity $[19,21$, $24,25,28,29,32,33,39,40,43,48,49]$. Analyses adjusting for major confounders were reported in twelve studies [21-23, 25, 26, 28, 29, 31, 40, 47-49] and seven studies reported follow-up until all patients were either deceased or discharged [19, 20, 29, 31, 39, 46, 49]. Twelve studies contained more than $10 \%$ missing data [20, 21, 23-25, 30-32, 41, 43, 46, 49]. Twelve studies reported confidence precision estimate of association of ACEI/ARB with outcomes [21-29, 40, 47, 49]. One study included 17 people prescribed ACEI/ARB in the control group [40]. The overall strength of association between ACEI/ARB and outcomes was low (Table 3). None of the studies investigated the relationships between ACEI/ARB dose and outcome and only five studies reported whether ACEI/ARBs were continued during admission [19, 27, 40, 41, 46]. Only one study reported the association of continuation or discontinuation of medication during hospitalisation and outcome [27]. Biological plausibility and specificity of exposure and outcome were poorly evaluated in most studies and there was a high risk of confounding.

\section{Association of ACEI/ARB prescription with severe or critical disease outcome}

The meta-analysis incorporated 1930 severe or critical disease outcomes in 8389 people prescribed ACEI/ARB vs. 3822 severe or critical disease outcomes in 20,989 people not prescribed these medications from all 26 studies. The risk of severe or critical disease outcome was greater in people prescribed ACEI or ARB than those who were not (RR 1.23, 95\% CI 1.06, 1.42, $Z$ = 2.73, $p=0.006)$. There was a high degree of heterogeneity $\left(I^{2}=88 \%\right)$ (Fig. 2). Sub-group analyses found that people prescribed ACEI (RR 1.33, 95\% CI 1.08, 1.63, $Z=$ $2.68, p=0.007$ ) or ARB (RR 1.28, 95\% CI 1.07, 1.52, $Z=$ $2.68, p=0.007)$ were at higher risk of severe or critical disease outcomes than those who were not prescribed these drugs (S2: Supp Fig 1-2). Amongst people with a history of hypertension, there was no association between prescription of these medications and severe or 


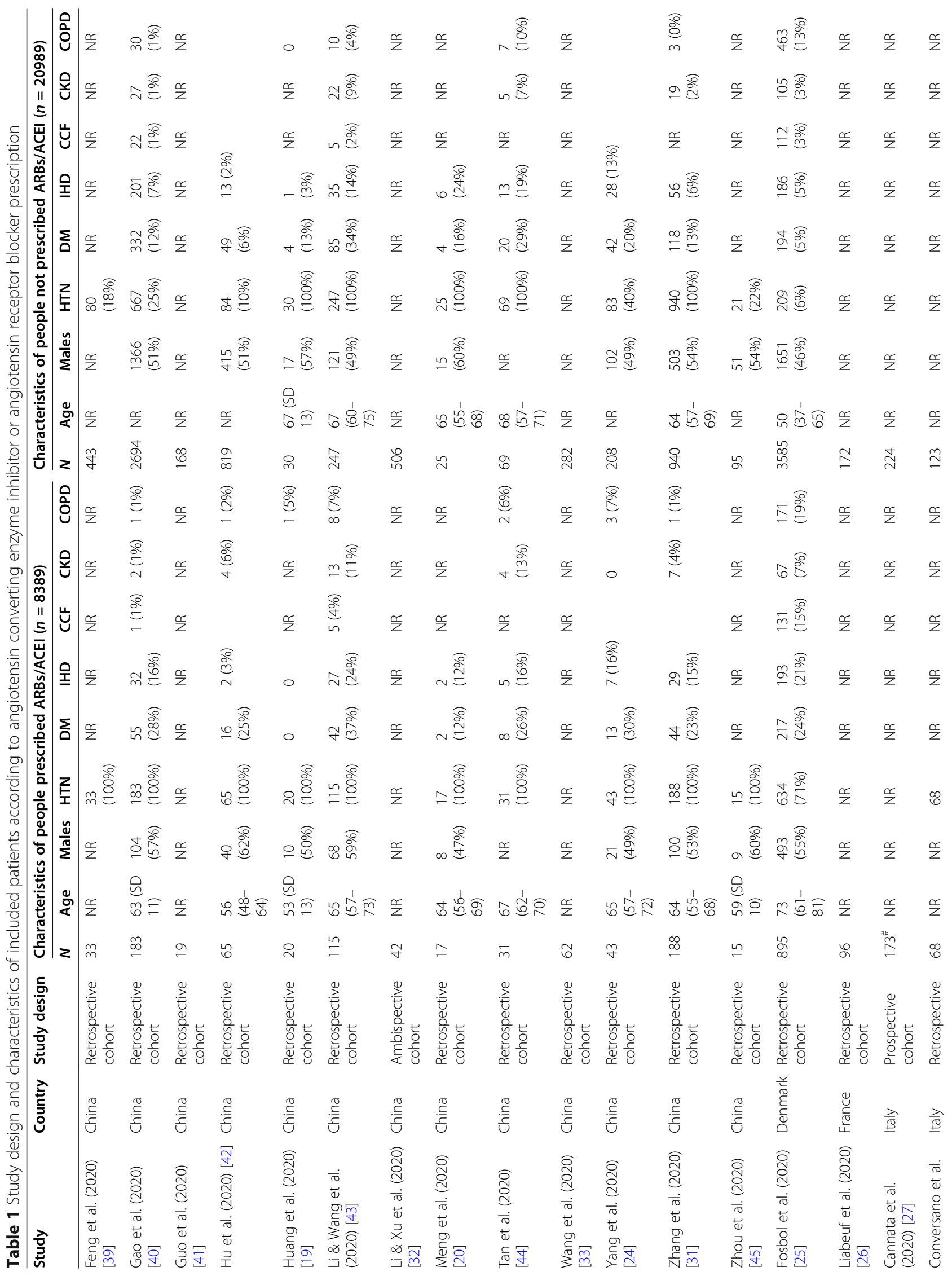




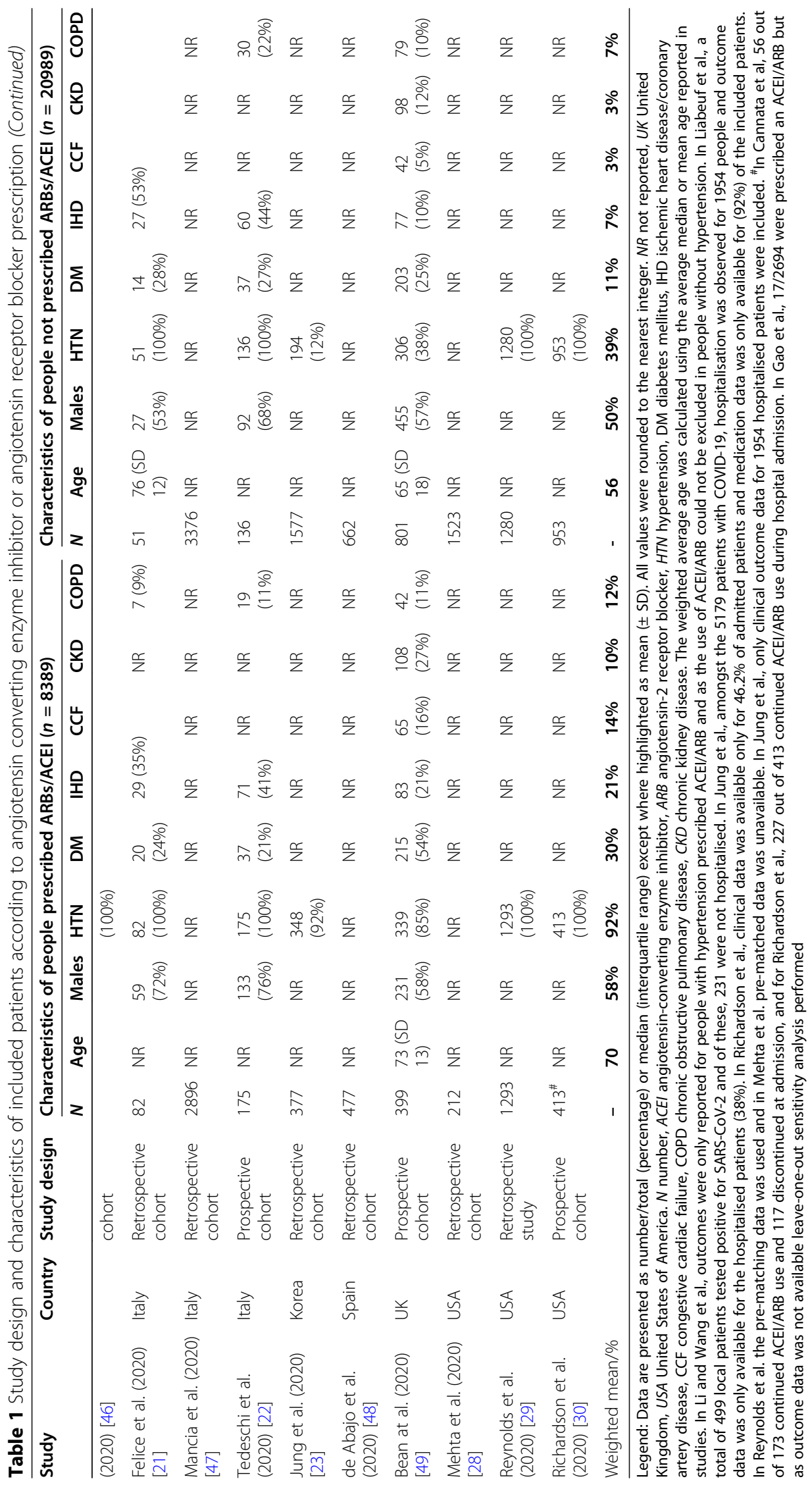


Table 2 Quality of included studies based on standardised criterion

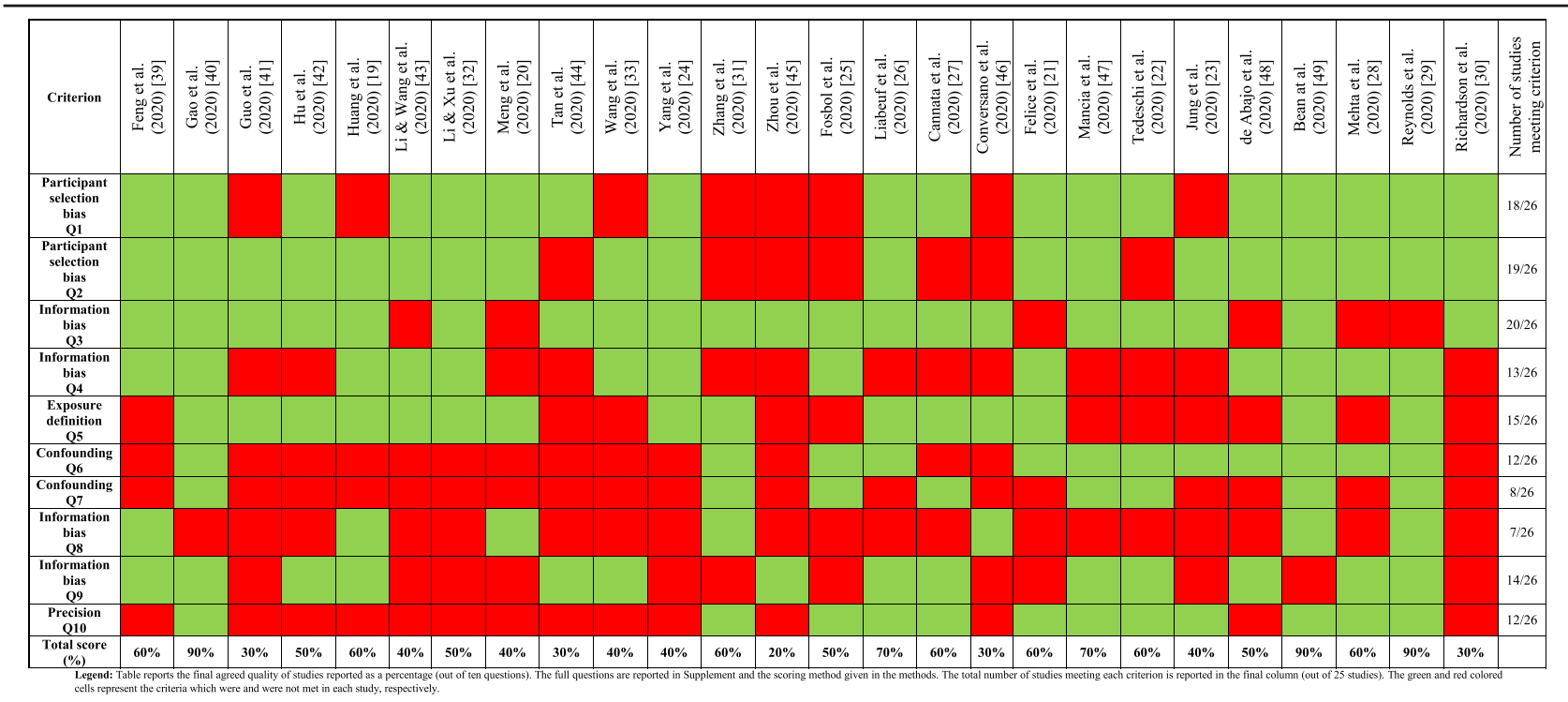

Legend: Table reports the final agreed quality of studies reported as a percentage (out of ten questions). The full questions are reported in Supplement and the scoring method given in "Material and methods." The total number of studies meeting each criterion is reported in the final column (out of 25 studies). The green and red coloured cells represent the criteria which were and were not met in each study, respectively

Table 3 Strength of association between angiotensin converting enzyme inhibitor or angiotensin receptor blocker prescription and COVID-19 outcome based on standardised criteria

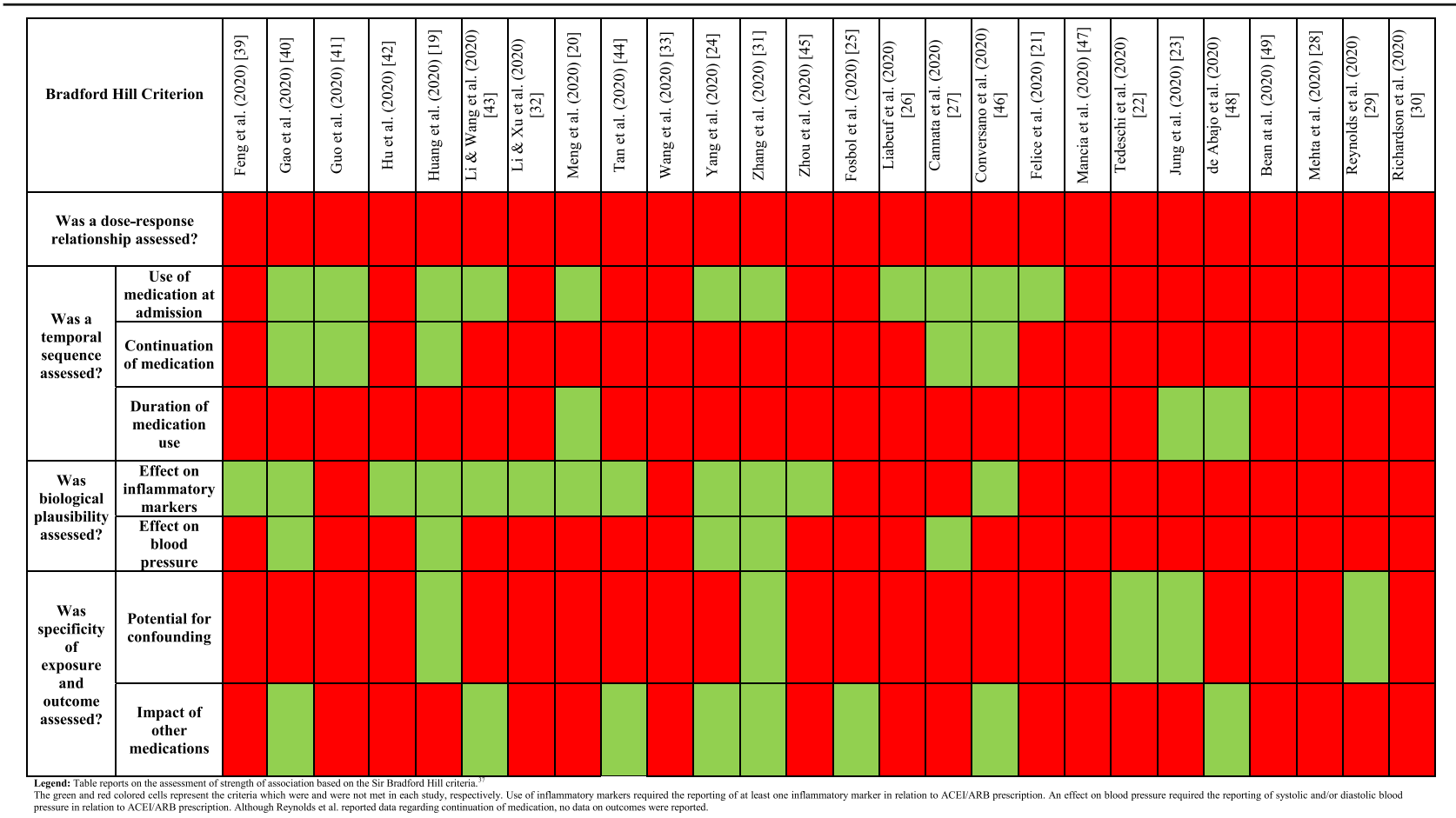

Legend: Table reports on the assessment of strength of association based on the Sir Bradford Hill criteria. ${ }^{37}$ The green and red coloured cells represent the criteria which were and were not met in each study, respectively. Use of inflammatory markers required the reporting of at least one inflammatory marker in relation to ACEI/ARB prescription. An effect on blood pressure required the reporting of systolic and/or diastolic blood pressure in relation to ACEI/ARB prescription. Although Reynolds et al. reported data regarding continuation of medication, no data on outcomes were reported 


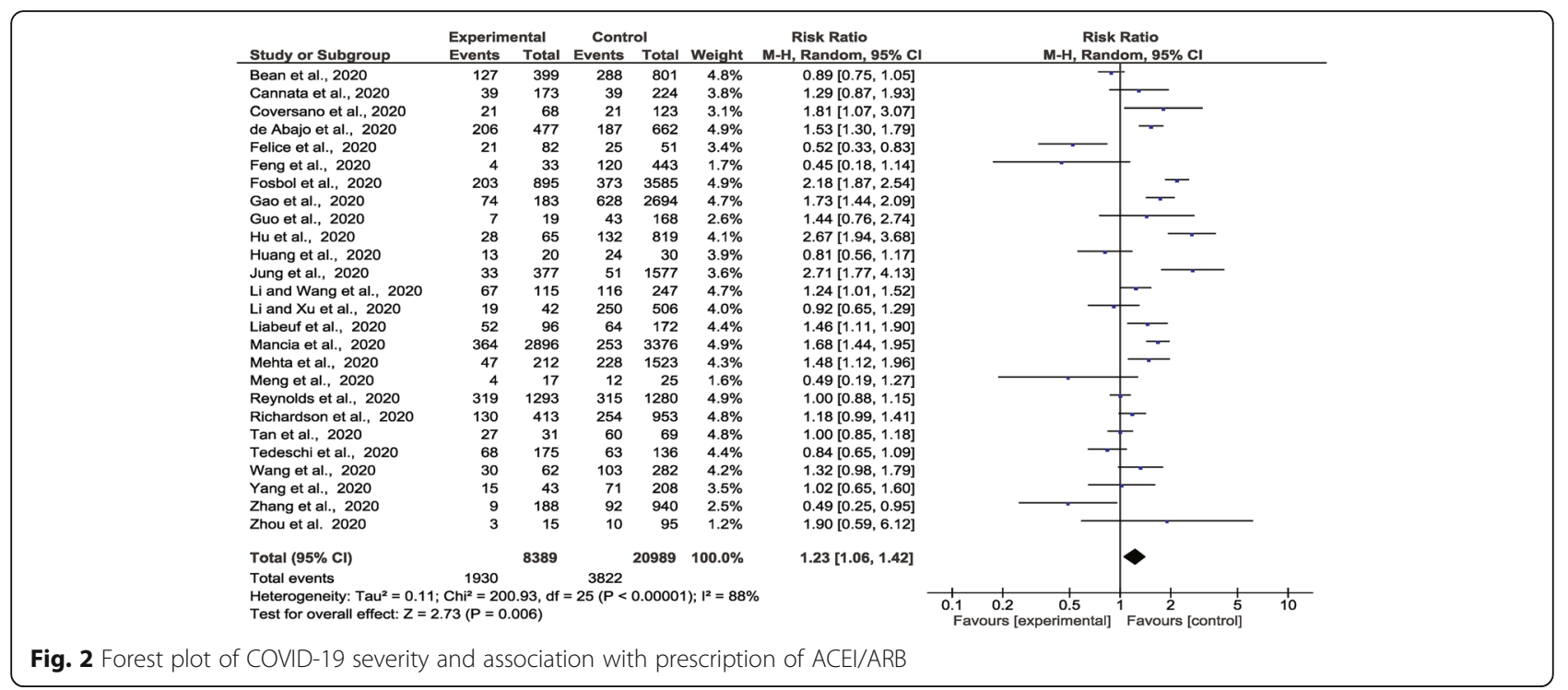

critical disease outcomes (S2: Supp Fig 3). Sensitivity analyses showed that when the analyses were restricted to people recruited from individual continents or highquality studies, there was no significant association between ACEI/ARB prescription (or ACEI alone or ARB alone) and severe or critical disease outcomes (S1: Supp Table 9-11). The funnel plots were asymmetrical (S2: Supp Fig 4-7).

\section{Association of ACEI/ARB prescription with COVID-19- related mortality}

There were 692 deaths in 3648 people prescribed ACEI/ ARB vs. 1375 deaths in 14,693 people not prescribed these medications reported from 21 studies. Metaanalysis showed no statistically significant association between ACEI/ARB prescription and mortality (RR 1.18,
95\% CI 0.92, 1.50, $Z=1.31, p=0.19$ ). There was a high degree of heterogeneity $\left(I^{2}=82 \%\right)$ (Fig. 3). Sub-group analyses found no significant associations between prescription of ACEI or ARB alone and mortality (S2: Supp Fig 8-9). A sensitivity analysis focused on people with a history of hypertension alone incorporated 246 deaths in 1164 people prescribed ACEI/ARB vs. 513 deaths in 2639 people not prescribed these medications from 11 studies. This found a lower risk of death in people prescribed ACEI or ARB (RR 0.72, 95\% CI 0.52, 0.99, $Z=$ 2.03, $p=0.04$ ) with a moderate degree of heterogeneity $\left(I^{2}=58 \%\right)$ (Fig. 4). Sensitivity analyses suggested that findings for the main analysis and class-specific analyses were not dependent on the inclusion of any individual studies and were similar when restricted to people recruited from individual continents or high-quality

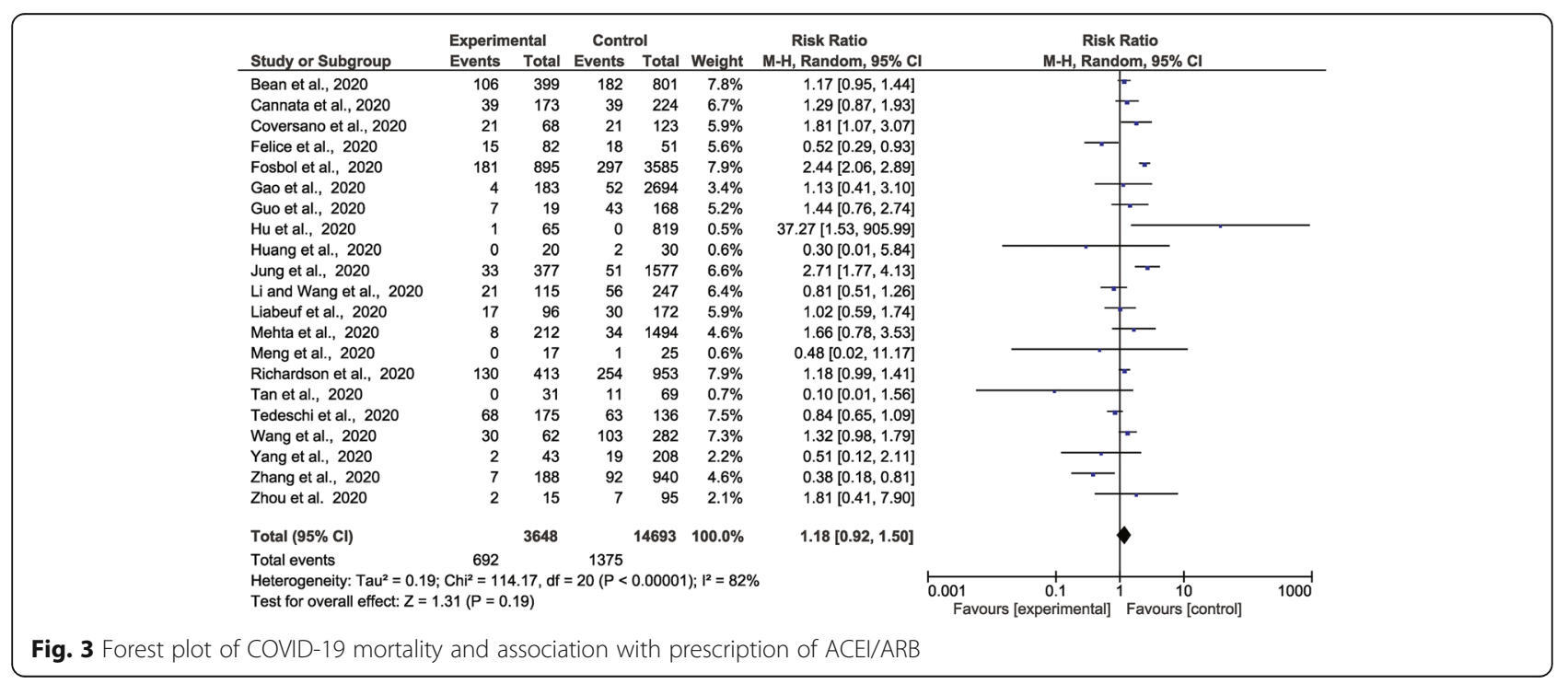




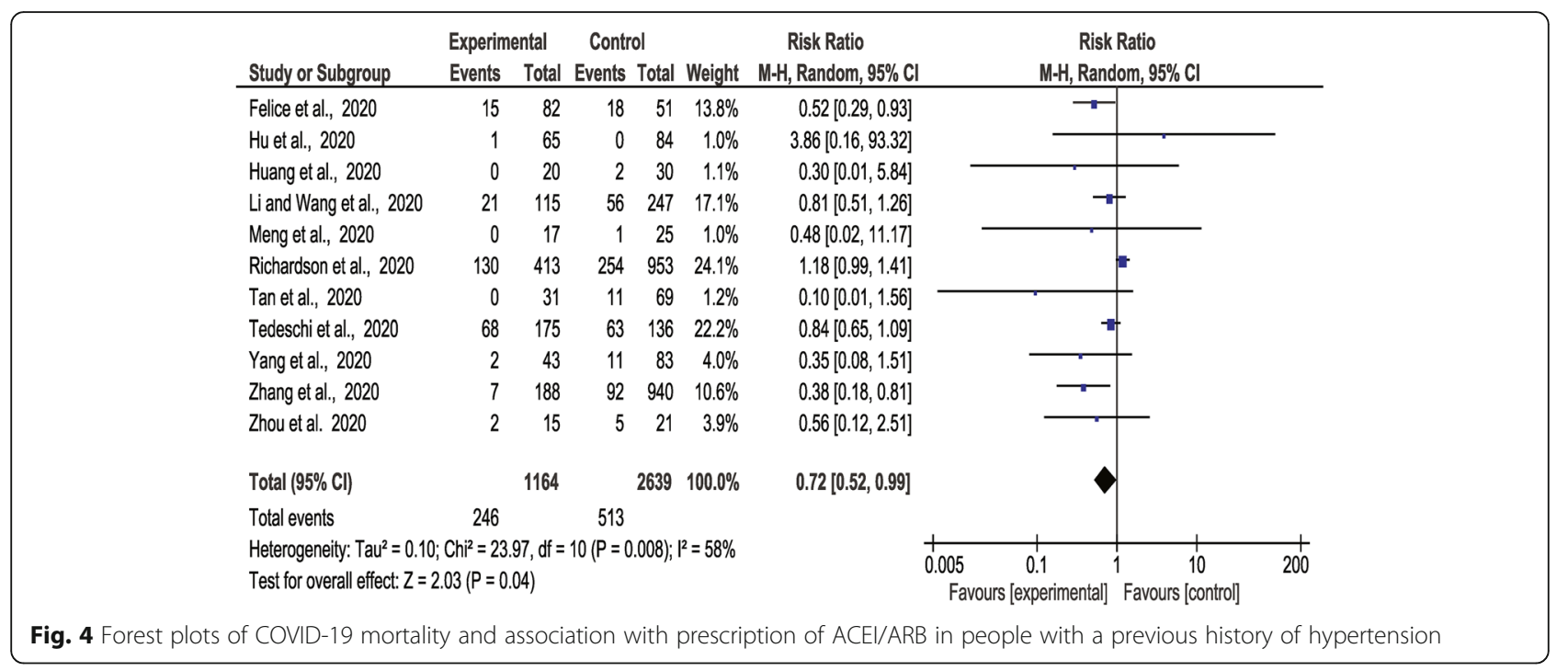

studies (S1: Supp Tables 11-13). The finding of the analysis restricted to people with hypertension was largely dependent on the inclusion of two studies (S1: Supp Table 13). The funnel plots were asymmetrical (S2: Supp Fig 4-7).

\section{Discussion}

Ideally, choices about drug prescription should be based on data from randomised controlled trials; however, such studies are not easy to perform during a pandemic. To our knowledge, this is one of the largest and only meta-analysis to pool data exclusively from published observational studies to examine whether an association exists between ACEI or ARB prescription and COVID19 outcome. The main meta-analyses showed that people prescribed ACEI/ARB had a higher risk of severe or critical disease outcomes. Observational studies are subject to biases that must be considered during interpretation. It is therefore important to highlight that people prescribed ACEI/ARB were older and more likely to be male and had higher prevalence of a number of co-morbidities, including hypertension, diabetes, IHD, CCF, CKD and COPD, that have been associated with worse outcome from COVID-19 [50-53]. Furthermore, the association between ACEI/ARB and severe or critical disease outcomes was not robust, being lost in sensitivity analyses restricted to people with hypertension, those recruited from individual continents or high-quality studies. There was also no association between drug prescription and mortality in most of the analyses except the one restricted to people with hypertension in which there was a $28 \%$ lower mortality in people prescribed either ACEIs or ARBs. The latter finding was not however robust in sensitivity analyses. Overall, these findings suggest that there is no robust published observational data that ACEI/ARB prescription is associated with worse or better outcome from COVID-19. Thus, the findings suggest no evidence to stop or start these medications in people admitted to hospital with COVID-19.

Since our search was conducted, there have been other meta-analyses published examining the relationship between ACEI/ARB prescription and COVID-19 outcomes [54-62]. These analyses (amongst others not described here) differ widely in their total number of included studies, study type(s) included, patient populations, inclusion of retracted studies [56], undertaking of quality assessment and use of quality assessment outcomes in interpreting the results and inclusion of pre-print articles $[56,59-62]$. These differences likely contributed to the conflicting findings between this and similar studies. Many analyses have found no significant difference in either COVID-19 severity or mortality related to ACEI/ ARB prescription $[55,56,58,61]$ whilst others have found significant reductions either for the whole population [54, 57,62] or in sub-analyses, such as for patients with hypertension $[59,60]$. No studies have found an increased risk of severe disease or mortality from COVID19 in relation to ACEI/ARB prescription. Some analyses also examined the association between ACEI/ARB prescription and the risk of COVID-19 infection, which also varied depending on the class of agent (significant reduction with ACEI but not ARB) [57], and sub-analyses of the patient population (significant increase but not when adjusting for patients with hypertension) [58].

The outcomes from COVID-19 found in this study were likely influenced by treatments received whilst in the hospital including the use of systemic steroids and anti-viral medication, but these were poorly reported in the included studies. At the time of writing, dexamethasone is the only medication with a proven reported 
mortality benefit in people infected with COVID-19 based on high-quality randomised controlled trial data [63]. Dexamethasone reduced deaths by one-third in patients receiving invasive mechanical ventilation compared to standard care [63]. Very few studies included in the current meta-analysis reported the in-patient treatment differences between people prescribed and notprescribed ACEI/ARB, and in the studies that did report in-patient treatments, several studies reported differences in the use of supportive therapies including greater use of corticosteroids during hospital admission in people prescribed ACEI/ARB [20, 23, 39, 41, 44].

Key elements to any systematic review are evaluations of study quality and strength of association. Only three $(12 \%)$ of the included studies were deemed high quality. The strength of association between exposure and outcome in the studies was also limited. Additionally, given the retrospective design of most studies, selection bias remains an important problem [31]. Although not explored in the current meta-analysis, whether the prescription of ACEI/ARB has an association with the incidence of COVID-19 still remains unclear although a lack of such association has been reported [64], though others are conflicting $[57,58]$.

This meta-analysis had a number of strengths and limitations. Strengths included the systematic approach and careful examination of the quality and strength of association using standardised tools and extensive sensitivity analyses $[13,35,65]$. It is possible that dual reporting of data from similar populations may have occurred. Sensitivity analyses were performed to minimise the effect of this on the overall outcome. Adjustment of analyses for confounding factors, such as older age, hypertension, diabetes, IHD and CKD, was not possible, and it is likely that the association of ACEI/ARB prescription and severe or critical disease outcomes resulted from residual confounding due to disproportional prevalence of risk factors in the two groups. We only included studies published in English in the search period listed. Lastly, the impact of protopathic and residual bias due to cessation or initiation of ACEI/ARB during hospital admission was not adequately assessed in almost all the included studies and is an important consideration.

\section{Conclusions}

This meta-analysis of published observational studies suggests that there is no robust published observational data that ACEI/ARB prescription is associated with worse or better outcome from COVID-19. Thus, similar to the recommendations from other studies, the findings suggest no evidence to stop or start these drugs in people admitted to the hospital with COVID-19.

\section{Abbreviations}

ACE2: Angiotensin-converting enzyme 2; ACEl: Angiotensin-converting enzyme inhibitor; ARB: Angiotensin receptor blocker; CCF: Congestive cardiac failure; Cl: Confidence interval; CKD: Chronic kidney disease; COPD: Chronic obstructive pulmonary disease; CRP: C-reactive protein; ICD-10: International Statistical Classification of Diseases and Related Health Problems Version 10; IHD: Ischaemic heart disease; MOOSE: Meta-analysis Of Observational Studies in Epidemiology; PRISMA: Preferred Reporting Items for Systematic Reviews and Meta-Analyses; RR: Risk ratio; WHO: World Health Organization

\section{Supplementary Information}

The online version contains supplementary material available at https://doi. org/10.1186/s13643-021-01802-6.

Additional file 1: S1: Additional Tables and Data.

Additional file 2: S2: Additional Plots and Figures.

\section{Acknowledgements}

The authors would like to thank the corresponding authors of included studies who responded in a timely manner to our requests for clarification and the provision of additional data.

\section{Authors' contributions}

Conceptualisation: MF and JG. Data curation: MF and AD. Formal Analysis: MF. Investigation: MF and AD. Methodology: MF, AD and JG. Project Administration: JG. Visualisation: MF. Writing original draft preparation: MF and AD. Writing review and editing: MF, AD and JG. The authors read and approved the final manuscript.

\section{Funding}

Funding from The Townsville Hospital and Health Services Study, Education and Research Trust Fund, James Cook University (Strategic Research Investment Fund) and Queensland Government supported this work. JG holds a Practitioner Fellowship from the National Health and Medical Research Council (1117061) and a Senior Clinical Research Fellowship from the Queensland Government, Australia. The funders played no role in study design, conduct, data collection, analysis and interpretation, and did not assist in manuscript preparation or review.

Availability of data and materials

Data are available from the corresponding author upon reasonable request.

\section{Declarations}

Ethics approval and consent to participate

Not applicable

Consent for publication

Not applicable

Competing interests

None of the authors have any relevant conflicts of interest to declare.

Author details

${ }^{1}$ Queensland Research Centre for Peripheral Vascular Disease, College of Medicine and Dentistry, James Cook University, Townsville, Queensland 4811, Australia. ${ }^{2}$ Department of Vascular and Endovascular Surgery, Townsville University Hospital, Townsville, Queensland, Australia. ${ }^{3}$ Australian Institute of Tropical Health and Medicine, James Cook University, Townsville,

Queensland, Australia.

Received: 10 January 2021 Accepted: 25 August 2021

Published online: 07 September 2021

\section{References}

1. Guo YR, Cao QD, Hong ZS, Tan YY, Chen SD, Jin HJ, et al. The origin, transmission and clinical therapies on coronavirus disease 2019 (COVID-19) outbreak - an update on the status. Mil Med Res. 2020;7(1):1-10. 
2. Igase $M$, Strawn $W B$, Gallagher PE, Geary RL, Ferrario CM. Angiotensin II AT1 receptors regulate ACE2 and angiotensin-(1-7) expression in the aorta of spontaneously hypertensive rats. Am J Physiol Heart Circ Physiol. 2005; 289(3):H1013-9. https://doi.org/10.1152/ajpheart.00068.2005.

3. Brojakowska A, Narula J, Shimony R, Bander J. Clinical Implications of SARSCoV-2 interaction with renin angiotensin system: JACC review topic of the week. J Am Coll Cardiol. 2020;75(24):3085-95. https://doi.org/10.1016/j.jacc.2 020.04.028.

4. Wang B, Li R, Lu Z, Huang Y. Does comorbidity increase the risk of patients with COVID-19: evidence from meta-analysis. Aging. 2020;12(7):6049-57. https://doi.org/10.18632/aging.103000.

5. Lippi G, Wong J, Henry BM. Hypertension and its severity or mortality in coronavirus disease 2019 (COVID-19): a pooled analysis. Pol Arch Intern Med. 2020;130(4):304-9. https://doi.org/10.20452/pamw.15272.

6. Vaduganathan M, Vardeny $\mathrm{O}$, Michel T, McMurray JJV, Pfeffer MA, Solomon SD. Renin-angiotensin-aldosterone system inhibitors in patients with Covid19. N Engl J Med. 2020;382(17):1653-9. https://doi.org/10.1056/NEJMsr2 005760

7. Grover A, Oberoi M. A systematic review and meta-analysis to evaluate the clinical outcomes in COVID-19 patients on angiotensin-converting enzyme inhibitors or angiotensin receptor blockers. Eur Heart J Cardiovasc Pharmacother. 2020. Epub 2020/06/17;7(2):148-57. https://doi.org/10.1093/ ehjcvp/pvaa064.

8. Zhang $X, Y U$ J, Pan LY, Jiang HY. ACEI/ARB use and risk of infection or severity or mortality of COVID-19: a systematic review and meta-analysis. Pharmacol Res. 2020;158:104927. https://doi.org/10.1016/j.phrs.2020.104927.

9. Mackey K, King VJ, Gurley S, Kiefer M, Liederbauer E, Vela K, et al. Risks and impact of angiotensin-converting enzyme inhibitors or angiotensin-receptor blockers on SARS-CoV-2 infection in adults. Ann Intern Med. 2020. Epub 2020/05/19;173(3):195-203. https://doi.org/10.7326/m20-1515.

10. Pirola CJ, Sookoian S. Estimation of renin-angiotensin-aldosterone-system (RAAS)-Inhibitor effect on COVID-19 outcome: a meta-analysis. J Infect. 2020. Epub 2020/06/01;81(2):276-81. https://doi.org/10.1016/j.jinf.2020.05.052.

11. Guo X, Zhu Y, Hong Y. Decreased mortality of COVID-19 with reninangiotensin-aldosterone system inhibitors therapy in patients with hypertension: a meta-analysis. Hypertension. 2020. Epub 2020/05/28;76(2): e13-4. https://doi.org/10.1161/hypertensionaha.120.15572.

12. Mehra MR, Desai SS, Kuy S, Henry TD, Patel AN. Cardiovascular disease, drug therapy, and mortality in Covid-19. N Engl J Med. 2020. Epub 2020/05/02; 382(25):e102. https://doi.org/10.1056/NEJMoa2007621.

13. Moher D, Liberati A, Tetzlaff J, Altman DG, Group P. Preferred reporting items for systematic reviews and meta-analyses: the PRISMA statement. PLoS Med. 2009;6(7):e1000097. https://doi.org/10.1371/journal.pmed.1 000097.

14. Stroup DF, Berlin JA, Morton SC, Olkin I, Williamson GD, Rennie D, et al. Meta-analysis of observational studies in epidemiology a proposal for reporting. Meta-analysis Of Observational Studies in Epidemiology (MOOSE) group. JAMA. 2000;283(15):2008-12. https://doi.org/10.1001/jama.283.15.2 008.

15. World Health Organization. Laboratory testing for coronavirus disease (COVID-19) in suspected human cases. 2020. 2020

16. World Health Organization. ICD 10: international statistical classification of diseases and related health problems: tenth revision. 2nd ed. 2004.

17. World Health Organization. Report of the WHO-China Joint Mission on Coronavirus Disease 2019 (COVID-19. 2020. 2020

18. World Health Organization. International guidelines for certification and classification (Coding) Of Covid-19 as cause of death. 2020.

19. Huang Z, Cao J, Yao Y, Jin X, Luo Z, Xue Y, et al. The effect of RAS blockers on the clinical characteristics of COVID-19 patients with hypertension. Annals of Translational Medicine. 2020;8(7):430. https://doi.org/10.21037/a tm.2020.03.229.

20. Meng J, Xiao G, Zhang J, He X, Ou M, Bi J, et al. Renin-angiotensin system inhibitors improve the clinical outcomes of COVID-19 patients with hypertension. Emerg Microbes Infect. 2020;9(1):757-60. https://doi.org/10.1 080/22221751.2020.1746200.

21. Felice C, Nardin C, Di Tanna GL, Grossi U, Bernardi E, Scaldaferri L, et al. Use of RAAS inhibitors and risk of clinical deterioration in COVID-19: results from an Italian cohort of 133 hypertensives. Am J Hypertens. 2020;33(10):944-8. https://doi.org/10.1093/ajh/hpaa096.

22. Tedeschi S, Giannella M, Bartoletti M, Trapani F, Tadolini M, Borghi C, et al. Clinical impact of renin-angiotensin system inhibitors on in-hospital mortality of patients with hypertension hospitalized for COVID-19. Clin Infect Dis. 2020. Epub 2020/04/28;71(15):899-901. https://doi.org/10.1093/ $\mathrm{cid} / \mathrm{ciaa492}$

23. Jung SY, Choi JC, You SH, Kim WY. Association of renin-angiotensinaldosterone system inhibitors with COVID-19-related outcomes in Korea: a nationwide population-based cohort study. Clin Infect Dis. 2020. Epub 2020/ 05/23;71(16):2121-8. https://doi.org/10.1093/cid/ciaa624.

24. Yang G, Tan Z, Zhou L, Yang M, Peng L, Liu J, et al. Effects of Angiotensin II receptor blockers and ACE (angiotensin-converting enzyme) inhibitors on virus infection, inflammatory status, and clinical outcomes in patients with COVID-19 and hypertension: a single-center retrospective study. Hypertension. 2020;76(1):51-8. https://doi.org/10.1161/HYPERTENSIONA HA.120.15143.

25. Fosbol EL, Butt JH, Ostergaard L, Andersson C, Selmer C, Kragholm K, et al. Association of angiotensin-converting enzyme inhibitor or angiotensin receptor blocker use with COVID-19 diagnosis and mortality. JAMA. 2020; 324(4):168-77. https://doi.org/10.1001/jama.2020.11301.

26. Liabeuf S, Moragny J, Bennis Y, Batteux B, Brochot E, Schmit JL, et al. Association between renin-angiotensin system inhibitors and COVID-19 complications. Eur Heart J Cardiovasc Pharmacother. 2020. Epub 2020/06/ 13. https://doi.org/10.1093/ehjcvp/pvaa062.

27. Cannata F, Chiarito M, Reimers B, Azzolini E, Ferrante G, My I, et al. Continuation versus discontinuation of ACE inhibitors or angiotensin II receptor blockers in COVID-19: effects on blood pressure control and mortality. Eur Heart J Cardiovasc Pharmacother. 2020. Epub 2020/06/06;6(6): 412-4. https://doi.org/10.1093/ehjcvp/pvaa056.

28. Mehta N, Kalra A, Nowacki AS, Anjewierden S, Han Z, Bhat P, et al. Association of use of angiotensin-converting enzyme inhibitors and angiotensin II receptor blockers with testing positive for coronavirus disease 2019 (COVID-19). JAMA Cardiol. 2020. Epub 2020/05/06;5(9):1020-6. https:// doi.org/10.1001/jamacardio.2020.1855.

29. Reynolds HR, Adhikari S, Pulgarin C, Troxel AB, Iturrate E, Johnson SB, et al. Renin-angiotensin-aldosterone system inhibitors and risk of Covid-19. N Engl J Med. 2020. Epub 2020/05/02;382(25):2441-8. https://doi.org/10.1056/ NEJMoa2008975.

30. Richardson S, Hirsch JS, Narasimhan M, Crawford JM, McGinn T, Davidson $\mathrm{KW}$, et al. Presenting characteristics, comorbidities, and outcomes among 5700 patients hospitalized with COVID-19 in the New York City area. JAMA. 2020. Epub 2020/04/23;323(20):2052-9. https://doi.org/10.1001/jama.2020. 6775.

31. Zhang P, Zhu L, Cai J, Lei F, Qin JJ, Xie J, et al. Association of Inpatient use of angiotensin converting enzyme inhibitors and angiotensin $\|$ receptor blockers with mortality among patients with hypertension hospitalized with COVID-19. Circulation Research. 2020;17:17 PubMed PMID: 32302265.

32. Li X, Xu S, Yu M, Wang K, Tao Y, Zhou Y, et al. Risk factors for severity and mortality in adult COVID-19 inpatients in Wuhan. J Allergy Clin Immunol. 2020. Epub 2020/04/16;146(1):110-8. https://doi.org/10.1016/j.jaci.2020.04. 006.

33. Wang $Y, L$ Lu $X, L i Y$, Chen $H$, Chen $T$, Su N, et al. Clinical course and outcomes of 344 intensive care patients with COVID-19. Am J Respir Crit Care Med. 2020;201(11):1430-4. https://doi.org/10.1164/rccm.202003-0736LE.

34. Sterne JA, Hernan MA, Reeves BC, Savovic J, Berkman ND, Viswanathan M, et al. ROBINS-I: a tool for assessing risk of bias in non-randomised studies of interventions. BMJ. 2016;355:i4919.

35. Hill AB. The environment and disease: association or causation? Proceedings of the Royal Society of Medicine. 1965;58:295-300.

36. Sterne JA, Gavaghan D, Egger M. Publication and related bias in metaanalysis: power of statistical tests and prevalence in the literature. Journal of Clinical Epidemiology. 2000;53(11):1119-29. https://doi.org/10.1016/S0895-43 56(00)00242-0.

37. Kulinskaya E, Morgenthaler S, Staudte RG. Combining statistical evidence. International Statistical Review. 2014;82(2):214-42. https://doi.org/10.1111/ insr.12037.

38. Higgins JP, Thompson SG. Quantifying heterogeneity in a meta-analysis. Stat Med. 2002;21(11):1539-58. Epub 2002/07/12. https://doi.org/10.1002/ sim.1186.

39. Feng Y, Ling Y, Bai T, Xie Y, Huang J, Li J, et al. COVID-19 with different severity: a multi-center study of clinical features. Am J Respir Crit Care Med. 2020;201(11):1380-8. https://doi.org/10.1164/rccm.202002-04450C.

40. Gao C, Cai Y, Zhang K, Zhou L, Zhang Y, Zhang X, et al. Association of hypertension and antihypertensive treatment with COVID-19 mortality: a 
retrospective observational study. Eur Heart J. 2020;41(22):2058-66. https:// doi.org/10.1093/eurheartj/ehaa433.

41. Guo T, Fan Y, Chen M, Wu X, Zhang L, He T, et al. Cardiovascular implications of fatal outcomes of patients with coronavirus disease 2019 (COVID-19). JAMA Cardiol. 2020. Epub 2020/03/29;5(7):811-8. https://doi. org/10.1001/jamacardio.2020.1017.

42. Hu J, Zhang X, Zhang X, Zhao H, Lian J, Hao S, et al. COVID-19 patients with hypertension have more severity condition, and ACEI/ARB treatment have no infulence on the clinical severity and outcome. J Infect. 2020. Epub 2020/06/01;81(6):979-97. https://doi.org/10.1016/j.jinf.2020.05.056.

43. Li J, Wang X, Chen J, Zhang H, Deng A. Association of renin-angiotensin system inhibitors with severity or risk of death in patients with hypertension hospitalized for coronavirus disease 2019 (COVID-19) infection in Wuhan, China. JAMA Cardiology. 2020;23:23. 32324209.

44. Tan ND, Qiu Y, Xing XB, Ghosh S, Chen MH, Mao R. Associations between angiotensin converting enzyme inhibitors and angiotensin II receptor blocker use, gastrointestinal symptoms, and mortality among patients with COVID-19. Gastroenterology. 2020;159(3):1170-2. https://doi.org/10.1053/j.ga stro.2020.05.034

45. Zhou X, Zhu J, Xu T. Clinical characteristics of coronavirus disease 2019 (COVID-19) patients with hypertension on renin-angiotensin system inhibitors. Clin Exp Hypertens. 2020;42(7):656-60. https://doi.org/10.1080/1 0641963.2020.1764018

46. Conversano A, Francesco M, Antonio N, Evgeny F, Marzia S, Fabio C, et al. RAAs inhibitors and outcome in patients with SARS-CoV-2 pneumonia. A case series study. Hypertension. 2020.

47. Mancia G, Rea F, Ludergnani M, Apolone G, Corrao G. Renin-angiotensinaldosterone system blockers and the risk of Covid-19. N Engl J Med. 2020 Epub 2020/05/02;382(25):2431-40. https://doi.org/10.1056/NEJMoa2006923.

48. de Abajo FJ, Rodríguez-Martín S, Lerma V, Mejía-Abril G, Aguilar M, GarcíaLuque A, et al. Use of renin-angiotensin-aldosterone system inhibitors and risk of COVID-19 requiring admission to hospital: a case-population study. Lancet. 2020;395(10238):1705-14. https://doi.org/10.1016/50140-6736(20)31 030-8.

49. Bean DM, Kraljevic Z, Searle T, Bendayan R, Kevin OG, Pickles A, et al. ACEinhibitors and angiotensin-2 receptor blockers are not associated with severe SARS-COVID19 infection in a multi-site UK acute Hospital Trust. Eur J Heart Fail. 2020. Epub 2020/06/03;22(6):967-74. https://doi.org/10.1002/ejhf.1 924.

50. Zheng Z, Peng F, Xu B, Zhao J, Liu H, Peng J, et al. Risk factors of critical \& mortal COVID-19 cases: a systematic literature review and meta-analysis. The Journal of infection. 2020:S0163-4453(20)30234-6. doi: https://doi.org/10.101 6/j.jinf.2020.04.021.

51. Mantovani A, Byrne CD, Zheng M-H, Targher G. Diabetes as a risk factor for greater COVID-19 severity and in-hospital death: a meta-analysis of observational studies. Nutrition, Metabolism and Cardiovascular Diseases. 2020;30(8):1236-48. https://doi.org/10.1016/j.numecd.2020.05.014.

52. Liu W, Tao ZW, Lei W, Ming-Li Y, Kui L, Ling Z, et al. Analysis of factors associated with disease outcomes in hospitalized patients with 2019 novel coronavirus disease. Chin Med J. 2020. Epub 2020/03/03;133(9):1032-8. https://doi.org/10.1097/cm9.0000000000000775.

53. Galbadage T, Peterson BM, Awada J, Buck AS, Ramirez DA, Wilson J, et al. Systematic review and meta-analysis of sex-specific COVID-19 clinical outcomes. Frontiers in Medicine. 2020;7:348.

54. Baral R, Tsampasian V, Debski M, Moran B, Garg P, Clark A, et al. Association between renin-angiotensin-aldosterone system inhibitors and clinical outcomes in patients with COVID-19: a systematic review and meta-analysis. JAMA Netw Open. 2021;4(3):e213594. https://doi.org/10.1001/jama networkopen.2021.3594.

55. Bavishi C, Whelton PK, Mancia G, Corrao G, Messerli FH. Renin-angiotensinsystem inhibitors and all-cause mortality in patients with COVID-19: a systematic review and meta-analysis of observational studies. J Hyperten. 2021;39(4):784-94. https://doi.org/10.1097/HJH.0000000000002784.

56. Biswas M, Kali MS. Association of angiotensin-converting enzyme inhibitors and angiotensin-receptor blockers with risk of mortality, severity or SARSCoV-2 test positivity in COVID-19 patients: meta-analysis. Sci Rep. 2021;11(1): 1-8. doi: https://doi.org/10.1038/s41598-021-84678-9, 5012.

57. Chu C, Zeng S, Hasan AA, Hocher CF, Krämer BK, Hocher B. Comparison of infection risks and clinical outcomes in patients with and without SARSCoV-2 lung infection under renin-angiotensin-aldosterone system blockade: systematic review and meta-analysis. Br J Pharmacol. 2021;87(6): 2475-92. https://doi.org/10.1111/bcp.14660.

58. Ma Z, Wang MP, Liu L, Yu S, Wu TR, Zhao L, et al. Does taking an angiotensin inhibitor increase the risk for COVID-19?-a systematic review and meta-analysis. Aging. 2021;13(8):10853. https://doi.org/10.18632/aging.2 02902.

59. Ren L, Yu S, Xu W, Overton JL, Chiamvimonvat N, Thai PN. Lack of association of antihypertensive drugs with the risk and severity of COVID-19: a meta-analysis. J Cardiol. 2021;77(5):482-91. https://doi.org/10.1016/j.jjcc.2 020.10.015.

60. Ssentongo AE, Ssentongo P, Heilbrunn ES, Lekoubou A, Du P, Liao D, et al. Renin-angiotensin-aldosterone system inhibitors and the risk of mortality in patients with hypertension hospitalised for COVID-19: systematic review and meta-analysis. Open Heart. 2020;7(2):e001353. https://doi.org/10.1136/ openhrt-2020-001353.

61. Xu J, Teng Y, Shang L, Gu X, Fan G, Chen Y, et al. The effect of prior angiotensin-converting enzyme inhibitor and angiotensin receptor blocker treatment on coronavirus disease 2019 (COVID-19) susceptibility and outcome: a systematic review and meta-analysis. Clin Infect Dis. 2021;72(11): e901-13. https://doi.org/10.1093/cid/ciaa1592.

62. Hasan SS, Kow CS, Hadi MA, Zaidi STR, Merchant HA. Mortality and disease severity among COVID-19 patients receiving renin-angiotensin system inhibitors: a systematic review and meta-analysis. Am J Cardiovasc Drugs. 2020;20(6):571-90. https://doi.org/10.1007/s40256-020-00439-5.

63. Horby P, Lim WS, Emberson J, Mafham M, Bell J, Linsell L, et al. Effect of dexamethasone in hospitalized patients with COVID-19: preliminary report. medRxiv. 2020:2020.06.22.20137273. doi: https://doi.org/10.1101/2020.06.22.2 0137273.

64. Gnavi R, Demaria M, Picariello R, Dalmasso M, Ricceri F, Costa G. Therapy with agents acting on the renin-angiotensin system and risk of severe acute respiratory syndrome coronavirus 2 infection. Clinical Infectious Diseases. 2020;71(16):2291-3. https://doi.org/10.1093/cid/ciaa634.

65. Grimes DA, Schulz KF. Bias and causal associations in observational research. The Lancet. 2002;359(9302):248-52. https://doi.org/10.1016/s0140-6736(02 007451-2.

\section{Publisher's Note}

Springer Nature remains neutral with regard to jurisdictional claims in published maps and institutional affiliations.

Ready to submit your research? Choose BMC and benefit from:

- fast, convenient online submission

- thorough peer review by experienced researchers in your field

- rapid publication on acceptance

- support for research data, including large and complex data types

- gold Open Access which fosters wider collaboration and increased citations

- maximum visibility for your research: over $100 \mathrm{M}$ website views per year

At BMC, research is always in progress.

Learn more biomedcentral.com/submissions 